\title{
Strength Comparison of FDM 3D Printed PLA Made by Different Manufacturers
}

\author{
Damir Hodžić, Adi Pandžić, Ismar Hajro, Petar Tasić \\ Faculty of Mechanical Engineering Sarajevo, Vilsonovo šetaliste 9, Sarajevo, Bosnia and Herzegovina
}

\begin{abstract}
Widely used additive manufacturing technique for plastic materials is Fused Deposition Modelling (FDM). The FDM technology has gained interest in industry for a wide range of applications, especially today when large number of different materials on the market are available. There are many different manufacturers for the same FDM material where the difference in price goes up to $50 \%$. This experimental study investigates possible difference in strength of the 3D printed PLA material of five different manufacturers. All specimens are 3D printed on Ultimaker S5 printer with the same printing parameters, and they are all the same colour.
\end{abstract}

Keywords - FDM, PLA, 3D printing, strength

\section{Introduction}

Today, 3D printing technologies (additive technologies, AM) are increasingly used to make products for a variety of applications and tend to replace conventional technologies where possible. Due to their capabilities such as rapid prototyping, flexibility, fabrication of complex geometries, a large number of materials, individual and even serial manufacturing, AM technologies are also topics of discussion of the EFFRA (European Factory Research Association of the Future).

DOI: 10.18421/TEM93-18

https://doi.org/10.18421/TEM93-18

Corresponding author: Adi Pandžić,

Faculty of Mechanical Engineering Sarajevo, Vilsonovo šetaliste 9, Sarajevo, Bosnia and Herzegovina.

Email: pandzic@mef.unsa.ba

Received: 11 June 2020.

Revised: 30 July 2020.

Accepted: 10 August 2020.

Published: 28 August 2020.

(cc) BY-NC-ND(C) 2020 Adi Pandžić et al; published by UIKTEN. This work is licensed under the Creative Commons Attribution-NonCommercial-NoDerivs 4.0 License.

The article is published with Open Access at www.temjournal.com
The FDM technology of 3D printing, based on material extrusion, is increasingly considered as a way to produce not just prototypes, but also final parts [1], [2], [3].

The most used 3D printing technology today is FDM, and mostly due to its ease of use and relatively low cost of the devices and materials used to make the products. Analysing industry 4.0, AM is gaining in importance, and product manufacturing with these methods provides many benefits, presented in Fig. 1., over traditional manufacturing techniques [4], [5], [6].

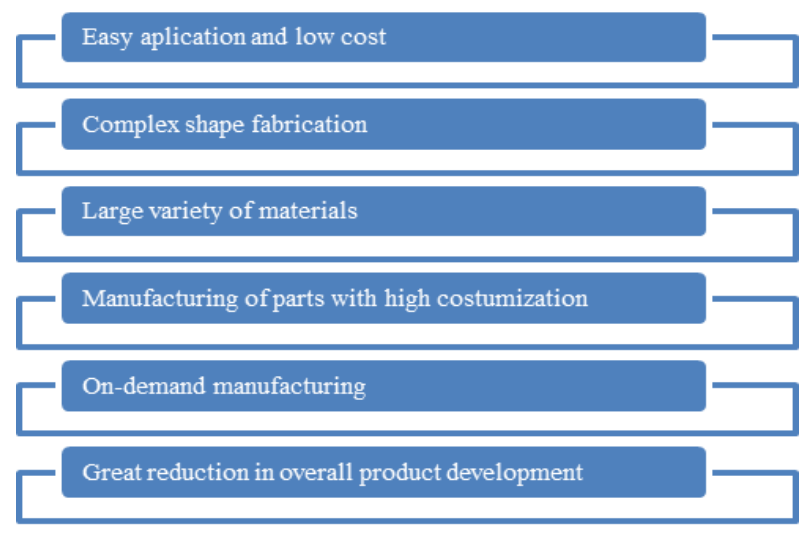

Figure 1. Advantages of additive over traditional manufacturing technologies

Fig. 2. shows schematic representation of product manufacturing process in case FDM $3 \mathrm{D}$ printing is used, giving all steps from CAD model to final product and its inspection.

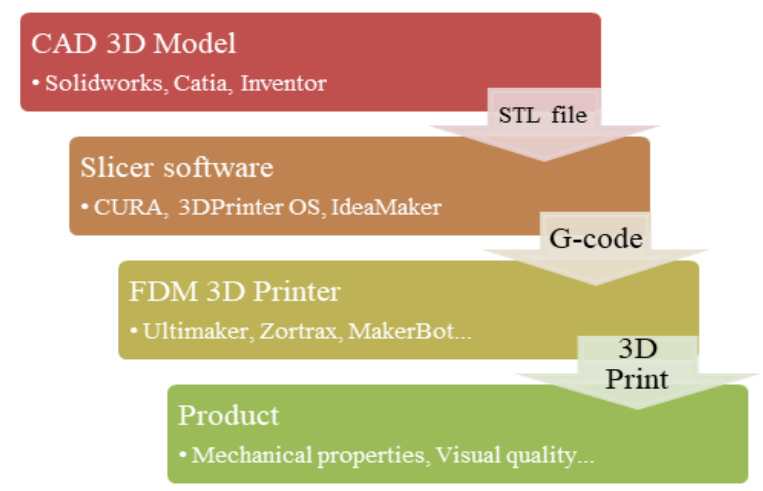

Figure 2. Schematic representation of FDM 3D printing from CAD to final product 
Creating CAD 3D model of product in STL format is the first step in the FDM process. CAD 3D model can be designed in many different CAD applications like SolidWorks, Catia and Inventor. Slicer, which is computer program used to prepare a 3D model of product for 3D printing (Ultimaker Cura, or other), is using STL format of CAD model to set all parameters and create G-code for 3D printing. Afterwards, the G-code is forwarded to FDM 3D printer via USB, SD card, wireless or over LAN, and 3D printing of designed product will start.

The FDM process is based on extruding thermoplastic material through extruder, which is usually located on the back of the 3D printer. The material is in the form of a wire and is wounded on spool from $750 \mathrm{~g}$ up to $8 \mathrm{~kg}$. The material from the extruder (material canister) is pushed to the heater block (3D printing head), where the material, in semi-liquid state, is applied layer by layer on print bed (built sheet). The FDM process is presented in Fig. 3.

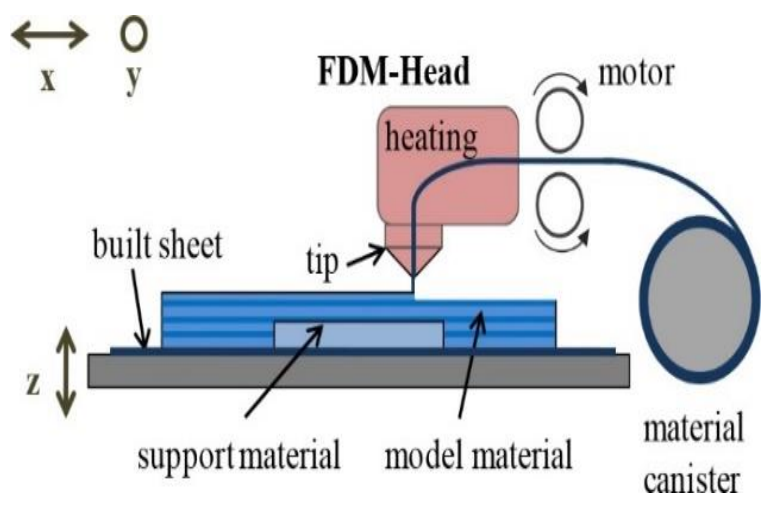

Figure 3. FDM 3D printing process [7]

Nowadays, by analysing materials for additive technologies, many different materials have been used or developed like different types of thermoplastics, metals, ceramics, composites, biodegradable polymers, short fiber composites, polymer-metal mixture materials etc [8].

There is a wide range of different materials and large number of FDM material manufacturers on the market available. Choosing the right material is critical to the success of good quality 3D printed product. A large number of manufacturers for the same material and lack of standards for additive technologies harden material selection. This is particularly important considering differences in prices for the same material (they can go up to 50\%).

This paper aims to analyse the difference in tensile strength properties of PLA FDM 3D printed material from different material manufacturers and to check whether the price is justified. All PLA samples have the same colour and they are all made by using the same printing parameters.

\section{Materials and Research Methodology}

Polylactic acid (PLA) is one of the most frequently used 3D printing materials. It belongs to the group of aliphatic polyesters, and it has been significantly researched and widely used material. The PLA can be substitute for conventional petrochemical polymers for industrial applications and also be used as a biomaterial for many medical applications. It is a natural and completely biodegradable polymer, obtained from renewable sources such as starch. As a completely aliphatic polymer, the PLA has played an essential role in replacing fossil-based polymers for certain applications. It is also known as a material that is easy to $3 \mathrm{D}$ print and has significantly higher mechanical properties compared to most other FDM polymeric polymers [9], [10], [11].

As the PLA is sensitive to humidity, environmental conditions should be taken into account during the production and testing of the PLA material, as they can be important quality factors [10], [12].

In this study, the PLA material from five different manufacturers is tested. Material specifications given by manufacturers are presented in Tab. 1 (mechanical properties) and Tab. 2 (printing parameters). For comparison, mechanical properties of injection moulded PLA (injection mould grade, 96:4 L:D ratio content, produced by NatureWorks Co. [11]) are given in Tab. 1.

Table 1. Mechanical properties of PLA

\begin{tabular}{||l|c|c|c||}
\hline Manufacturer & $\begin{array}{c}\text { Yield } \\
\text { Strength } \\
\text { (MPa) }\end{array}$ & $\begin{array}{c}\text { Tensile } \\
\text { Strength } \\
\text { (MPa) }\end{array}$ & $\begin{array}{c}\text { Elongation } \\
\text { at break } \\
(\%)\end{array}$ \\
\hline 3D Republika & 70,0 & $\mathrm{n} / \mathrm{a}$ & 20,0 \\
\hline Ultimaker & 49,5 & $\mathrm{n} / \mathrm{a}$ & 5,2 \\
\hline DevilDesign & $\mathrm{n} / \mathrm{a}$ & $\mathrm{n} / \mathrm{a}$ & 160,0 \\
\hline PrimaSelect & $\mathrm{n} / \mathrm{a}$ & 110,0 & 160,0 \\
\hline PM Filament & $\mathrm{n} / \mathrm{a}$ & $\mathrm{n} / \mathrm{a}$ & $\mathrm{n} / \mathrm{a}$ \\
\hline Moulded PLA & 70,0 & 73,0 & 7,0 \\
\hline
\end{tabular}

Table 2. Printing parameters of PLA

\begin{tabular}{||l|c|c||}
\hline Manufacturer & $\begin{array}{c}\text { Wire } \\
\text { Diameter } \\
(\mathbf{m m})\end{array}$ & $\begin{array}{c}\text { Printing } \\
\text { Temperature } \\
\left({ }^{\circ} \mathbf{C}\right)\end{array}$ \\
\hline 3D Republika & 2,85 & $205 \pm 10$ \\
\hline Ultimaker & 2,85 & 210 \\
\hline DevilDesign & 2,85 & $200-235$ \\
\hline PrimaSelect & 2,85 & $190-220$ \\
\hline PM Filament & 2,90 & $200-230$ \\
\hline
\end{tabular}

Experimental methodology is presented in Fig. 4. According to ISO 527-2 dogbone-type tensile testing specimens are prepared, and specimen dimensions are presented in Fig. 5. CAD model of specimen was designed in Solidworks, prepared in STL format for 
3D printing and used in CURA slicer for preparing 3D printing parameters. To avoid possible interferences on the results, all specimens were 3D printed with the same 3D printer (Ultimaker S5), printing parameters, nozzle diameter $(0.4 \mathrm{~mm})$, colour (white) and position on build plate. Specimens were 3D printed in "flat" orientation.

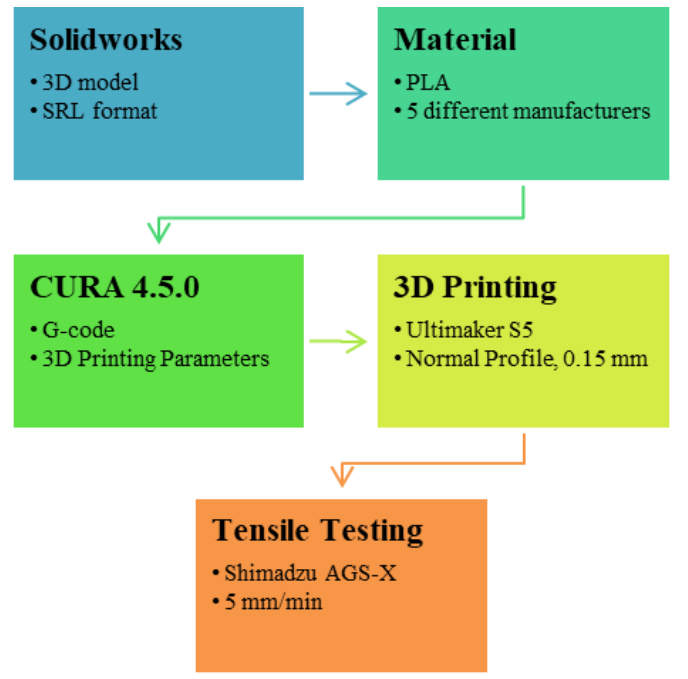

Figure 4. Experimental methodology

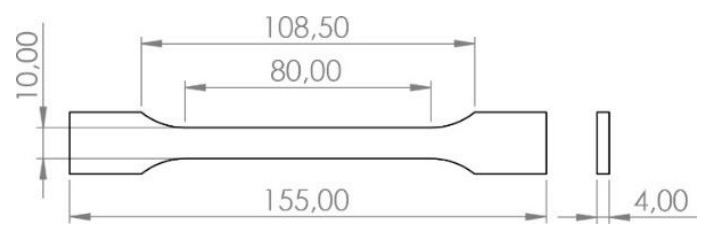

Figure 5. Dogbone-type specimen according to ISO 527-2

G-code was prepared with CURA slicer version 4.5. Predefined 3D printing parameters are used by choosing "Normal profile $0.15 \mathrm{~mm}$ " in CURA slicer, and main parameters like infill design, nozzle size, layer height, wall thickness and printing speed are given in Table 3.

Table 3. Principal $3 D$ printing parameters

\begin{tabular}{|l|c|}
\hline Nozzle & $0.40 \mathrm{~mm}$ \\
\hline Layer height & $0.15 \mathrm{~mm}$ \\
\hline Wall thickness & $1.00 \mathrm{~mm}$ \\
\hline Infill density & $100 \%$ \\
\hline Print speed & $70.00 \mathrm{~mm} / \mathrm{s}$ \\
\hline
\end{tabular}

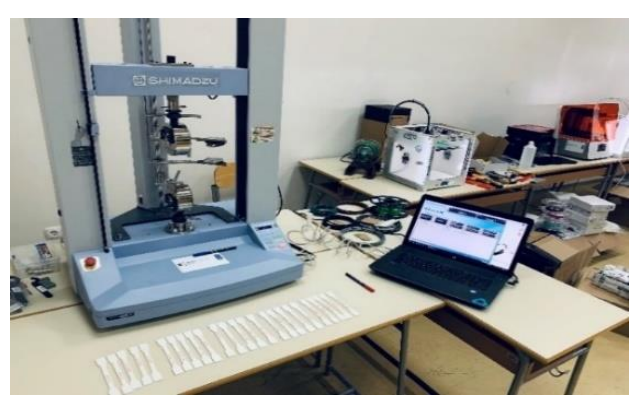

Figure 6. Shimadzu AGS-X Std tensile testing machine
For every manufacturer, five specimens are prepared and total of 25 specimens were examined. After 3D printing, the tensile testing was carried out using Shimadzu AGS-X Std tensile machine (Fig. 6.). According to ISO 527-2 specimens are tested at strain rate of $5 \mathrm{~mm} / \mathrm{min}$. For monitoring and collecting data, Trapezium-X software is used, and Stress-Strain diagrams are presented in Fig. 7. At the end, the results are analysed in Excel and they are presented in further text.

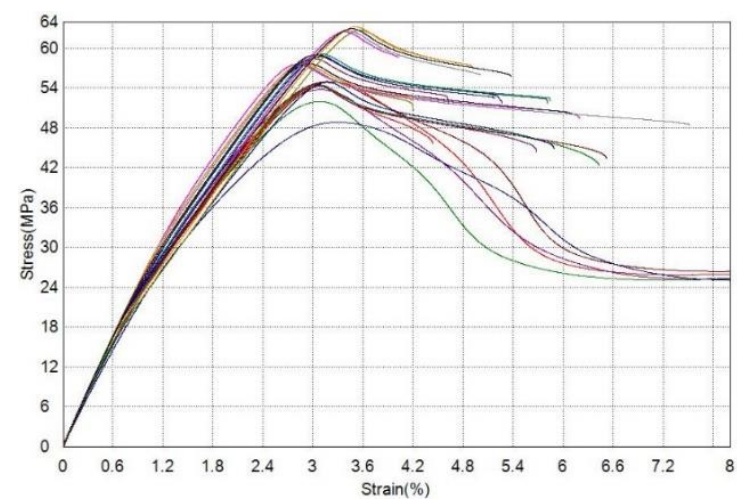

Figure 7. Stress-Strain diagrams for all tested specimens

\section{Results and Discussion}

After testing all specimens, the experimental data were collected and analysed. The presented data are the mean values of 5 examined samples for every PLA manufacturer. Maximal forces $\left(F_{\mathrm{m}}\right)$ that the PLA materials from certain manufacturer can withstand were compared and are presented in Fig. 8.

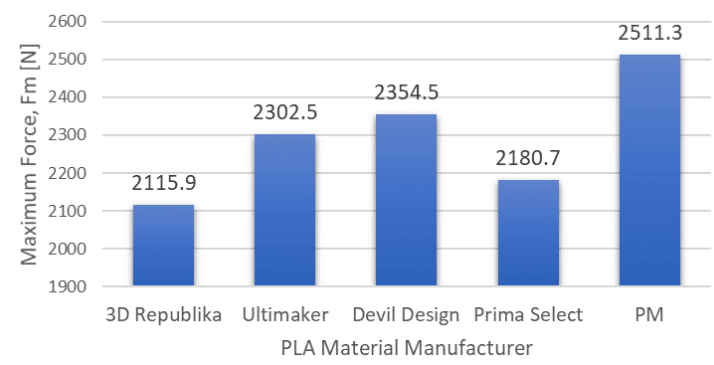

Figure 8. Maximum force that PLA material can withstand

The PLA material from PM Filament can withstand the highest $(2511.3 \mathrm{~N})$ and from 3D Republika the lowest (2115.9 N) force before break.

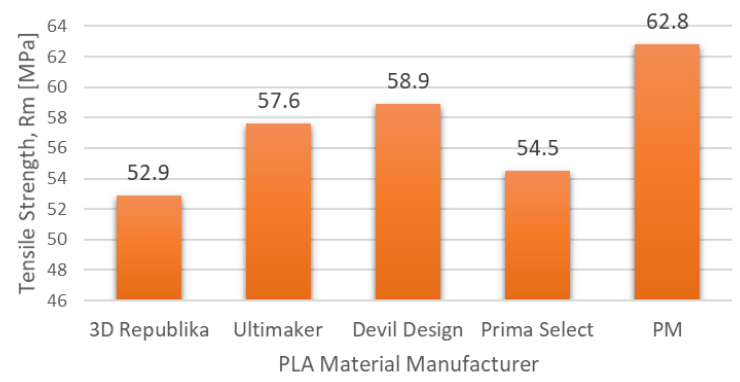

Figure 9. Tensile strength for different manufacturers 
The PLA material from PM Filament is showing the highest tensile strength $(62.7 \mathrm{MPa})$, while the material from 3D Republika is showing the lowest tensile strength (52.9 MPa). Analysing all five PLA materials, it can be seen that there is a difference in tensile strength up to $17 \%$.

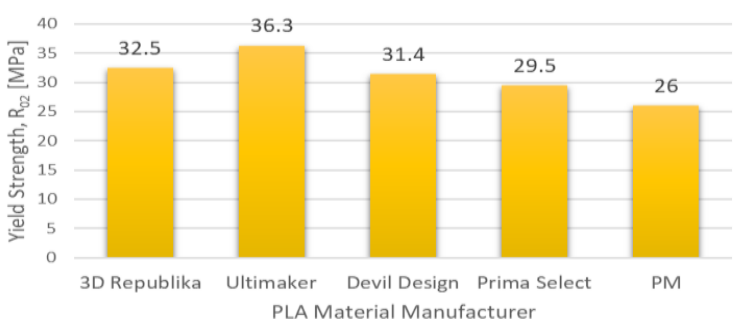

Figure 10. Yield strength for different manufacturers

Analysing yield strength $\left(R_{0.2}\right)$, it can be seen that the PLA from Ultimaker demonstrated the highest (36.3 MPa) and the PLA from PM Filament the lowest (26.0 MPa, 33\% lower than the best) value.

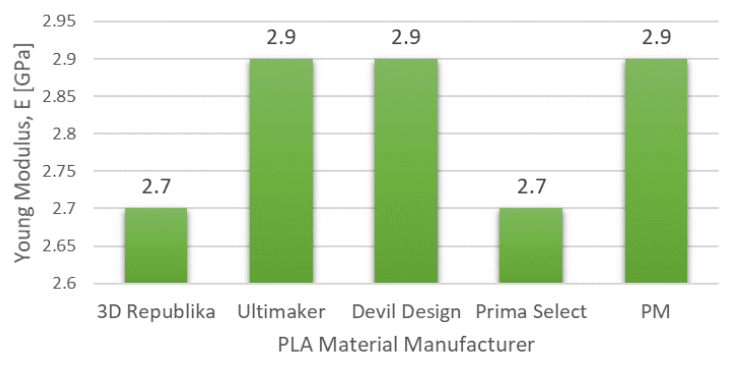

Figure 11. Young modulus for different manufacturers

The PLA from Ultimaker, Devil Design and PM Filament have shown Young modulus of $2.9 \mathrm{GPa}$, while the PLA from 3D Republika and Prima Select have shown $2.7 \mathrm{GPa}$. Variation among samples is $7 \%$.

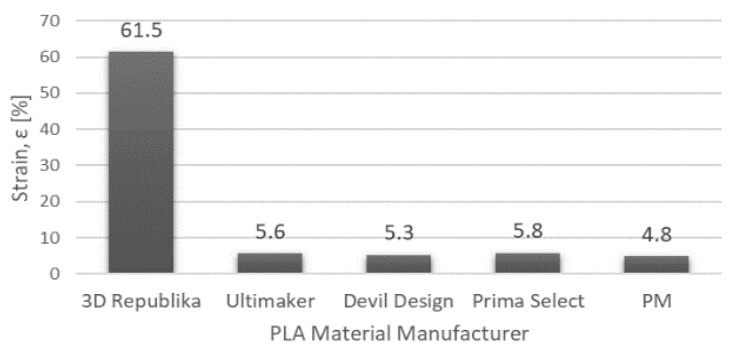

Figure 12. Strain for different manufacturers

Strains shown in Fig. 12. show unusual behaviour of the PLA from 3D Republika, with value over 60 $\%$. This is very interesting since the PLA is known as material with low strain (visible by results for other manufacturers). Furthermore, from Fig. 13. it can be seen that the strain for the PLA from 3D Republika varies from $40 \%$ to $90 \%$. There is clear difference between the PLA from 3D Republika and other manufacturers, up to $170 \%$.

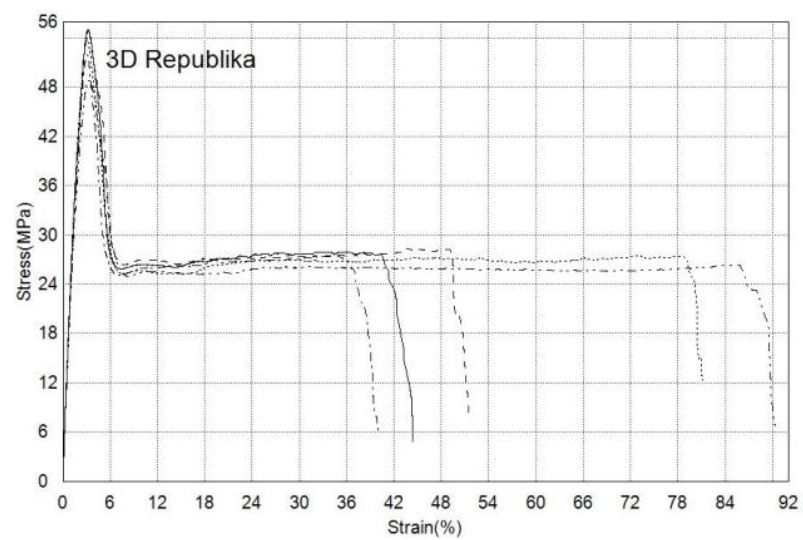

Figure 13. Stress-Strain diagram for all tested specimens of $3 D$ Republika PLA manufacturer

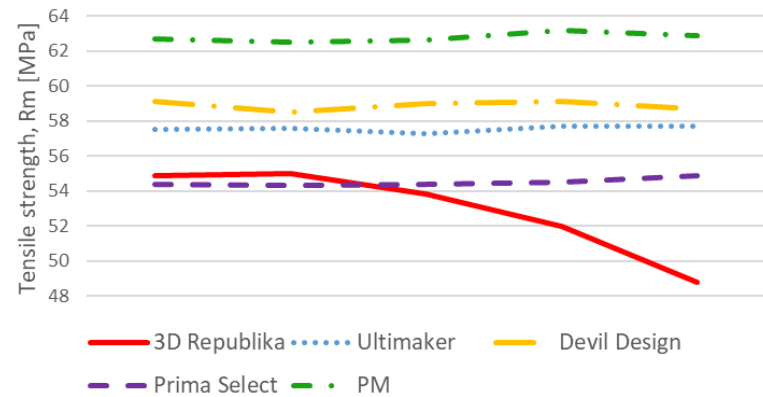

Figure 14. Repeatability of $R_{m}$ results

The repeatability (i.e. scattering) of the results for all PLA material manufacturers are analysed. From the diagram in Fig. 14., it can be seen that there is a slightly greater scattering of tensile strength results $\left(R_{\mathrm{m}}\right)$ for 3D Republika PLA manufacturer, where the difference in results is up to $12 \%$.

For all PLA manufacturers, the scattering of the strain results is visible in Fig. 15. The repeatability of strain results for the 3D Republika material are presented in Fig. 16. (scattering up to 68\%).

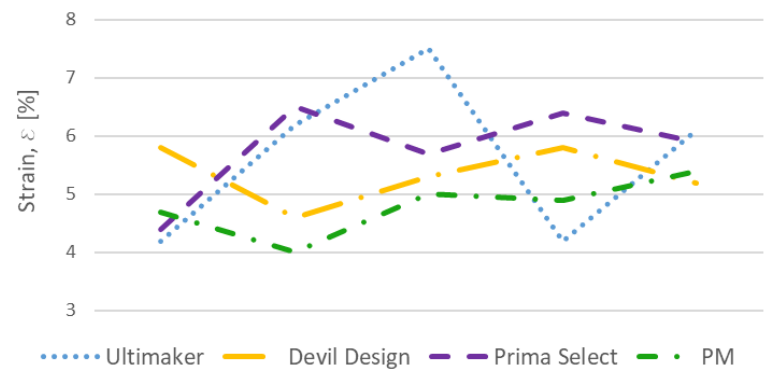

Figure 15. Repeatability of strain results

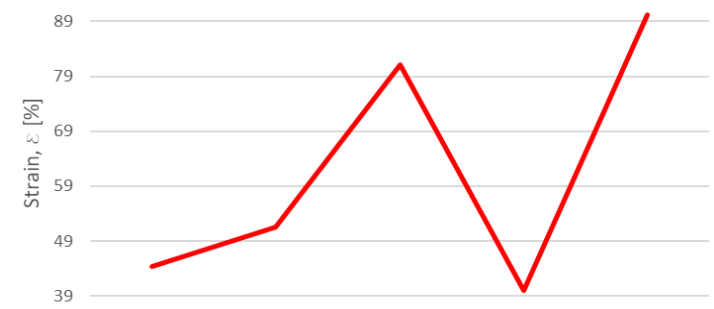

Figure 16. Repeatability of Strain results for 3D Republika 


\section{Conclusion}

By analysing the tensile properties of FDM 3D printed PLA material from different manufacturers, it can be noticed that differences are visible, even though all specimens are 3D printed under the same conditions. Variations are:

- Maximum tensile force $\left(F_{\mathrm{m}}\right)$ and tensile strength $\left(R_{\mathrm{m}}\right)$ have differences up to $17 \%$.

- Yield strength $\left(R_{0.2}\right)$ has differences up to $33 \%$.

- Differences in Young modulus $(E)$ are up to $7 \%$.

- Strain data shown differences up to $170 \%$.

Results of repeatability (scattering) for all tested material manufacturers are analysed, and looking at the tensile strength, a slightly greater result scattering of 3D Republika manufacturer can be seen. Other material manufacturers exhibited similar tensile strength during tests.

The strain results scattering is also visible and are significantly more expressed. Strain results scattering for the PLA from Ultimaker goes up to $56 \%$, and for 3D Republika up to $68 \%$.

Remarkably interesting and positive behaviour was shown by 3D Republika PLA material, where strain varies from $40 \%$ up to $90 \%$, which is not a common occurrence for a PLA material.

It is possible to note the differences when comparing values of strength properties stated by manufacturers (i.e. given in material specifications) and results presented in this paper (i.e. obtained by testing). One of the certain reasons is the lack of standards for FDM 3D printed materials that prescribe the method of testing mechanical properties.

What distinguishes Ultimaker from other manufacturers included in this research is inclusion of testing rate among other specifications of their PLA. This is an important fact, especially when there are no standards that specify testing rate required to perform tensile or other material testing.

When it comes to the engineering application of products made with FDM technologies, it is particularly important to know the mechanical properties of 3D printed material. Also, it is important to have a standard or other procedure that will guarantee the mechanical properties stated on the material specification.

Tensile test rate $(\mathrm{mm} / \mathrm{min})$ is interesting to be analysed in future research, as well as to analyse its relationship to the strength properties of the material. It is important to do similar research on other AM materials.

\section{References}

[1]. Abeykoon, C., Sri-Amphorn, P., \& Fernando, A. (2020). Optimization of fused deposition modeling parameters for improved PLA and ABS 3D printed structures. International Journal of Lightweight Materials and Manufacture, 3(3), 284-297.

[2]. Floor, J. W. (2015). Getting a grip on the Ultimaker 2. Tensile strength of 3D printed PLA: a systematic investigation [dissertation]. TU Delft: Delft University of Technology

[3]. Pandzic, A., Hodzic, D., \& Milovanovic, A. (2019). Influence of Material Colour on Mechanical Properties of Pla Material in Fdm Technology. Annals of DAAAM \& Proceedings, 30.

[4]. Gibson, I., Rosen, D., \& Stucker, B. (2015). Introduction and basic principles. In Additive manufacturing technologies (pp. 1-18). Springer, New York, NY.

[5]. Polak, R., Sedlacek, F., \& Raz, K. (2017, January). Determination of FDM printer settings with regard to geometrical accuracy. In Proceedings of the 28th DAAAM International Symposium (pp. 0561-0566).

[6]. Pandzic, A., Hodzic, D., \& Milovanovic, A. (2019). Effect of Infill Type and Density on Tensile Properties of Plamaterial for Fdm Process. Annals of DAAAM \& Proceedings, 30.

[7]. Schöppner, V., \& KTP, K. P. (2011). Mechanical properties of fused deposition modeling parts manufactured with Ultem* 9085. In Proceedings of 69th Annual Technical Conference of the Society of Plastics Engineers (ANTEC'11)(Vol. 2, pp. 12941298).

[8]. Casavola, C., Cazzato, A., Moramarco, V., \& Pappalettere, C. (2016). Orthotropic mechanical properties of fused deposition modelling parts described by classical laminate theory. Materials \& design, 90, 453-458.

[9]. Sikora, P., Gnatowski, A., \& Gołębski, R. (2019). Tests of mechanical properties of semicrystalline and amorphous polymeric materials produced by 3D printing. In MATEC Web of Conferences (Vol. 254, p. 06003). EDP Sciences.

[10]. Valerga, A. P., Batista, M., Salguero, J., \& Girot, F. (2018). Influence of PLA filament conditions on characteristics of FDM parts. Materials, 11(8), 1322.

[11]. Farah, S., Anderson, D. G., \& Langer, R. (2016). Physical and mechanical properties of PLA, and their functions in widespread applications-A comprehensive review. Advanced drug delivery reviews, 107, 367-392.

[12]. Kariz, M., Sernek, M., \& Kuzman, M. K. (2018). Effect of humidity on 3D-printed specimens from wood-PLA filaments. Wood Res, 63, 917-922. 